\title{
Quantification of Mitochondrial Dynamics in Fission Yeast
}

Leeba Ann Chacko and Vaishnavi Ananthanarayanan*

Centre for BioSystems Science and Engineering, Indian Institute of Science, Bangalore 560012, India *For correspondence: vaishnavi@iisc.ac.in

[Abstract] Mitochondria are double-membraned organelles responsible for several functions in the cell including energy production, calcium signaling, and cellular metabolism. An equilibrium between fission and fusion events of mitochondria is required for their proper functioning. Mitochondrial morphologies have been quantified in yeast using image processing modules such as MitoGraph and MitoLoc. However, the dynamics of mitochondrial fission and fusion have not been analyzed in these methods. Here, we present a method for measuring mitochondrial morphologies, as well as estimation of fission and fusion frequencies of mitochondria in individual fission yeast cells whose mitochondria are fluorescently-tagged or stained. The latter relies on counting of individual mitochondria upon signal filtering in each frame of a time-lapse. Taken together, we present a simple protocol for analyzing mitochondrial dynamics, which can easily be adopted to other model systems.

Keywords: Mitochondria, Mitochondrial dynamics, Mitochondrial fission, Mitochondrial fusion, Live-cell imaging, Fluorescence microscopy, Cell biology, Schizosaccharomyces pombe

[Background] Mitochondria are essential organelles present in the form of tubular networks within cells and constantly undergo fission and fusion events throughout the cell cycle. The rate of fission and fusion events determine the morphology of the mitochondria and this is a crucial determinant of their function (Mishra and Chan, 2016). Several factors contribute to the changes in morphology of the mitochondria. For instance, mitochondrial fission can be induced by stress, metabolic state, aging and in certain diseases (Sprenger and Langer, 2019). On the contrary, mitochondrial fusion can be induced to enhance cellular respiration in starved conditions and to dilute the effects of damaged mitochondrial DNA that may be present inside the cell (Westermann, 2010). Additionally, mitochondrial dynamics can drastically vary between cell types depending on the metabolic need of the given cell type. Since mitochondrial dynamics and thereby form are direct readouts for mitochondrial and cellular function, it is imperative to accurately measure these properties.

Early quantification efforts involved the use of qualitative descriptors to assess diverse mitochondrial morphologies. In recent times, computational image processing algorithms are being used to robustly quantify the differences in mitochondrial morphologies. For instance, the image processing module 'MitoLoc' uses the 3D reconstruction and analysis software, 'MitoMap' (a plugin for ImageJ) to define an object using Otsu thresholding and then calculates mitochondrial fragmentation, condensation and tubularity using mitochondrial shape descriptors such as mitochondrial size, position and integrity to differentiate the diverse mitochondrial phenotypes in budding yeast (Vowinckel et al., 2015). MitoLoc calculates the fragmentation of mitochondria using a fragmentation index $f$, which is defined as the sum 
of relative fragment volumes that individually constitute less than $20 \%$ of the total mitochondrial volume. Another open-source image analysis platform named 'MitoGraph' has been employed to quantify mitochondrial morphology in both yeast and mammalian cells (Viana et al., 2015; Harwig et al., 2018).

MitoGraph is an automated image processing software which performs graph theory-based quantitative analysis of mitochondrial networks by calculating the volumes of three-dimensional organelles in living cells. For both of these modules to provide accurate morphological data, it is imperative to utilize the best practices for imaging mitochondria by using the most optimal mitochondrial markers as well as high resolution imaging techniques. However, both of these modules do not provide quantitative measurements for mitochondrial fission and fusion dynamics. Here, we detail a simple method for quantifying both mitochondrial morphologies, as well as fission and fusion dynamics.

\section{Materials and Reagents}

1. Glass-bottom confocal dish, $35 \times 10 \mathrm{~mm}, \mathrm{PP}$, Sterile (SPL, catalog number: 100350)

2. Reusable Bottle Top Filter (Tarsons, catalog number: 50060 )

3. Membrane filter with $0.22 \mu \mathrm{m}$ pore size (Millipore, catalog number: GSWP04700)

4. Kimwipes disposable wipers (Sigma-Aldrich, catalog number: Z188956)

5. Schizosaccharomyces pombe cells expressing fluorescently-labeled mitochondria or fission yeast cells stained with MitoTracker dye. Wild-type $S$. pombe cells can be obtained from National BioResource Project, Japan (https://nbrp.jp)

6. Lectin from Bandeiraea simplicifolia (Sigma-Aldrich, catalog number: L3759), store at $2-8{ }^{\circ} \mathrm{C}$

7. Adenine (HiMedia, catalog number: TC082), store below $30^{\circ} \mathrm{C}$

8. Histidine (HiMedia, catalog number: GRM050), store below $30^{\circ} \mathrm{C}$

9. Leucine (HiMedia, catalog number: GRM054), store below $30^{\circ} \mathrm{C}$

10. Uracil (HiMedia, catalog number: GRM264), store below $30^{\circ} \mathrm{C}$

11. L- Lysine (HiMedia, catalog number: RM3028), store below $30^{\circ} \mathrm{C}$

12. MitoTracker ${ }^{\mathrm{TM}}$ Orange CMTMRos (Thermo Fisher, catalog number: M7510), store at -5 to $-30{ }^{\circ} \mathrm{C}$

13. $\mathrm{MgCl}_{2} \cdot 6 \mathrm{H}_{2} \mathrm{O}$ (HiMedia, catalog number: $\mathrm{MB} 040$ ), store below $30^{\circ} \mathrm{C}$

14. $\mathrm{CaCl}_{2} \cdot 2 \mathrm{H}_{2} \mathrm{O}$ (HiMedia, catalog number: MB034), store below $30^{\circ} \mathrm{C}$

15. $\mathrm{KCl}$ (HiMedia, catalog number: GRM3934), store below $30^{\circ} \mathrm{C}$

16. $\mathrm{NaCl}$ (HiMedia, catalog number: $\mathrm{MB} 023$ ), store below $30^{\circ} \mathrm{C}$

17. $\mathrm{Na}_{2} \mathrm{SO}_{4}$ (HiMedia, catalog number: MB209), store below $30^{\circ} \mathrm{C}$

18. Pantothenic acid (HiMedia, catalog number: CMS178), store at $2-8^{\circ} \mathrm{C}$

19. Nicotinic acid (HiMedia, catalog number: CMS177), store below $30^{\circ} \mathrm{C}$

20. Inositol (HiMedia, catalog number: GRM102), store below $30^{\circ} \mathrm{C}$

21. Biotin (HiMedia, catalog number: TC096), store at $2-8{ }^{\circ} \mathrm{C}$

22. Boric acid (HiMedia, catalog number: MB007), store below $30^{\circ} \mathrm{C}$

23. $\mathrm{MnSO}_{4}$ (HiMedia, catalog number: GRM1381), store below $30^{\circ} \mathrm{C}$

24. $\mathrm{ZnSO}_{4} \cdot 7 \mathrm{H}_{2} \mathrm{O}$ (HiMedia, catalog number: MB233), store below $30^{\circ} \mathrm{C}$ 
25. $\mathrm{FeCl}_{2} \cdot 6 \mathrm{H}_{2} \mathrm{O}$ (HiMedia, catalog number: GRM6353), store below $30^{\circ} \mathrm{C}$

26. Molybdic acid (Sigma-Aldrich, 232084), store at room temperature

27. KI (HiMedia, catalog number: GRM252), store below $30^{\circ} \mathrm{C}$

28. $\mathrm{CuSO}_{4} \cdot 5 \mathrm{H}_{2} \mathrm{O}$ (HiMedia, catalog number: GRM630), store below $30^{\circ} \mathrm{C}$

29. Citric acid (HiMedia, catalog number: GRM1023), store below $30^{\circ} \mathrm{C}$

30. Yeast extract (HiMedia, catalog number: RM027), store below $30^{\circ} \mathrm{C}$

31. Glucose (Sigma-Aldrich, catalog number: G8270), store at room temperature

32. Potassium hydrogen phthalate (HiMedia, catalog number: GRM2405), store below $30^{\circ} \mathrm{C}$

33. $\mathrm{Na}_{2} \mathrm{HPO}_{4}$ (HiMedia, catalog number: MB024), store below $30{ }^{\circ} \mathrm{C}$

34. $\mathrm{KH}_{2} \mathrm{PO}_{4}$ (Sigma-Aldrich, catalog number: $\mathrm{P} 5655$ ), store at room temperature

35. $\mathrm{NH}_{4} \mathrm{Cl}$ (HiMedia, catalog number: TC092), store below $30^{\circ} \mathrm{C}$

36. Agar powder, bacteriological (Himedia, catalog number: GRM026), store below $30^{\circ} \mathrm{C}$

37. $\mathrm{NaOH}$

38. Phosphate buffered saline (see Recipes)

39. EMM: Edinburgh Minimal Medium with appropriate supplements (see Recipes)
a. 50x Salt stock
b. 1,000x Vitamin stock
c. $10,000 x$ Mineral stock

40. YE: Yeast Extract with supplements (see Recipes)

\section{Equipment}

1. Orbital shaking Incubator (Ascension Innovations, model: Al-100)

2. Laser scanning (point/line) or spinning disk confocal microscope

We used the confocal mode of an InCell Analyzer 6000 (GE Healthcare) Imaging system with $60 x / 0.7$ N.A. objective, fitted with an sCMOS 5.5MP camera having an $x-y$ pixel separation of 108, and 405, 488, 561 and $640 \mathrm{~nm}$ laser lines

3. Standard vertical autoclave (Equitron, model: 7431STWL.AFE.113)

4. Laminar airflow chamber

\section{Software}

1. IN Cell Analyzer Acquisition Software v.4.6 (GE Healthcare) or any other confocal microscopy system-specific software

2. Fiji/lmageJ (http://fiji.sc/Fiii, Schindelin et al., 2012)

3. MATLAB software v. $2015 \mathrm{~b}$ or above (MathWorks, https://in.mathworks.com) 


\section{Procedure}

A. Preparation of $S$. pombe cells for imaging

1. Culture the yeast cells overnight by adding a loopful of cells (that have grown for at least a day in solid YE media) into $1 \mathrm{ml}$ of liquid YE with appropriate supplements. Grow the cells at $30^{\circ} \mathrm{C}$ for $12 \mathrm{~h}$ at $200 \mathrm{rpm}$ to $\mathrm{OD}_{600}$ of 0.4-0.9.

2. Subculture $200 \mu \mathrm{l}$ from the overnight culture into $1 \mathrm{ml}$ of fresh medium and grow at $30^{\circ} \mathrm{C}$ for $\sim 2$ $\mathrm{h}$ prior to imaging at $200 \mathrm{rpm}$.

3. Cover the surface of a $35 \mathrm{~mm}$ (No. 1) glass bottom dish with $25 \% \mathrm{NaOH}$ solution for $\sim 2 \mathrm{~h}$ to make the surface hydrophilic. Wash the dish twice with sterilized water and wipe the surface with Kimwipes.

4. Drop $2 \mu \mathrm{l}$ of lectin ( $2 \mathrm{mg} / \mathrm{ml}$ in PBS) onto the dish and spread evenly using an inoculation loop.

5. Allow the lectin to dry completely inside the laminar airflow at room temperature for 10-15 min.

6. Meanwhile, wash cells once by spinning them down and resuspending them in $1 \mathrm{ml}$ of EMM liquid medium.

7. If cells are already expressing fluorescently-labeled mitochondria (e.g., Cox4-GFP/RFP), proceed directly to Step A10, else follow Steps A7-A9 below to stain mitochondria with MitoTracker dye.

8. Dissolve MitoTracker Orange/DeepRed in DMSO at a concentration of $1 \mathrm{mM}$ and dilute it in liquid EMM to a stock solution of $1 \mu \mathrm{M}$. This stock solution can be stored at $-20^{\circ} \mathrm{C}$.

9. On the day of the experiment, freshly prepare $200 \mathrm{nM}$ of MitoTracker Orange/DeepRed from the stock solution by diluting with EMM. Incubate cells with $1 \mathrm{ml}$ of $200 \mathrm{nM}$ MitoTracker Orange/DeepRed solution for $15-30 \mathrm{~min}$ at $30^{\circ} \mathrm{C}$.

10. After incubation, wash the cells thrice in $1 \mathrm{ml}$ of liquid EMM to eliminate background fluorescence from unincorporated dye, and finally resuspend cells in $1 \mathrm{ml}$ of liquid EMM medium.

11. Transfer $200 \mu \mathrm{l}$ of cells resuspended in liquid EMM to the lectin-coated glass bottom dish.

12. Incubate the cell suspension on the glass bottom dish for $10 \mathrm{~min}$ at room temperature.

13. Wash out unbound cells and add $200 \mu \mathrm{l}$ of liquid EMM to the dish.

14. Image at room temperature $\left(\sim 25^{\circ} \mathrm{C}\right)$.

B. Obtaining time-lapse images to observe mitochondrial dynamics

1. Transfer cells to the stage of the confocal microscope.

2. Visualize mitochondria labeled with GFP or RFP using the $488 \mathrm{~nm}$ and $561 \mathrm{~nm}$ laser lines along with 525/20 and 605/52 $\mathrm{nm}$ bandpass emission filters respectively. Alternatively, visualize mitochondria stained with the MitoTracker Orange using the $561 \mathrm{~nm}$ laser line along with the 605/52 $\mathrm{nm}$ bandpass emission filter. The signal-to-noise ratio must be at least 1.5.

3. Capture mitochondrial dynamics by obtaining time-lapse images that are $12 \mathrm{~s}$ apart, for a total time of $\sim 4 \mathrm{~min}$, with Z-stacks for each timepoint with $0.5 \mu \mathrm{m}$ step-size encompassing the full cell ( $\sim 5$ steps). 
4. Save the time-lapse images in an appropriate format, such as TIFF.

\section{Data analysis}

A. Identification of mitochondria and measurement of mitochondrial parameters in Fij//mage J

1. Open time-lapse images obtained using Fij/lmageJ.

2. Ensure that the pixel to $\mu \mathrm{m}$ conversion for the image files is accurate by checking 'Set scale' in Fij//mageJ.

3. Crop individual cells in the field of view.

4. Apply 'Mean' filter with an appropriate radius which is sufficient to reduce background noise, while still maintaining separation between individual mitochondria. In Figure 1, we used a radius of 2 pixels.

5. Identify mitochondria in the images either manually or based on intensity thresholding (Figure 1).

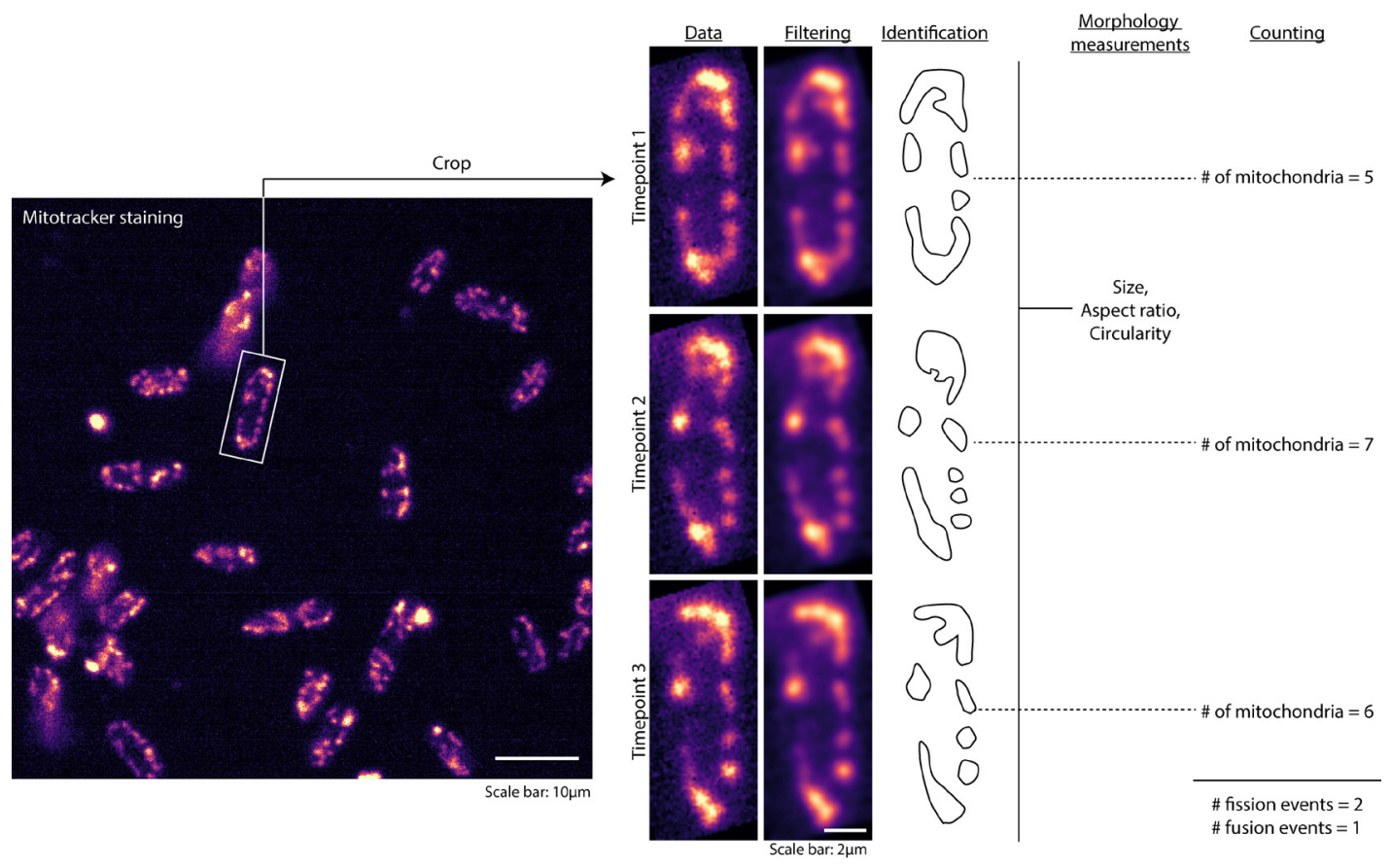

Figure 1. Analysis of mitochondrial dynamics. Workflow of analysis of the time-lapse images obtained, including cropping, image filtering, identification of mitochondria, measurement of morphology and counting.

6. If identifying mitochondria manually, draw regions of interest (ROIs) around mitochondria in each frame using the freehand selection tool.

7. In the 'Set measurements' function of Fij//mageJ, check the following options: Shape descriptors, Fit ellipse and Stack Position.

8. If identifying mitochondria using intensity thresholding, use the 'Analyze particles' function to 
display mitochondrial measurements, else run the 'Measure' function on each timepoint of the time-lapse images.

9. Save the measurements in appropriate format such as .txt or .csv (Figure 2).

\begin{tabular}{|c|c|c|c|c|c|c|c|c|c|}
\hline 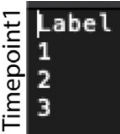 & $\begin{array}{l}\text { Area } \\
5.469 \\
0.258 \\
2.113\end{array}$ & $\begin{array}{l}\text { Major } \\
4.245 \\
0.602 \\
3.345\end{array}$ & $\begin{array}{l}\text { Minor } \\
1.646 \\
0.546 \\
0.804\end{array}$ & $\begin{array}{l}\text { Angle } \\
40.084 \\
134.999 \\
52.292\end{array}$ & $\begin{array}{l}\text { Circ. } \\
0.158 \\
1.000 \\
0.304\end{array}$ & $\begin{array}{l}\text { Slice } \\
1 \\
1 \\
1\end{array}$ & $\begin{array}{l}\text { AR } \\
2.588 \\
1.101 \\
4.159\end{array}$ & $\begin{array}{l}\text { Round } \\
0.386 \\
0.908 \\
0.240\end{array}$ & $\begin{array}{l}\text { Solidity } \\
0.552 \\
0.936 \\
0.577\end{array}$ \\
\hline 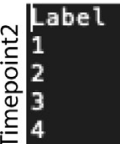 & $\begin{array}{l}\text { Area } \\
0.868 \\
0.528 \\
2.911 \\
3.028\end{array}$ & $\begin{array}{l}\text { Major } \\
1.454 \\
1.309 \\
3.696 \\
4.002\end{array}$ & $\begin{array}{l}\text { Minor } \\
0.761 \\
0.514 \\
1.003 \\
0.963\end{array}$ & $\begin{array}{l}\text { Angle } \\
20.899 \\
27.893 \\
43.608 \\
31.157\end{array}$ & $\begin{array}{l}\text { Circ. } \\
0.520 \\
0.663 \\
0.185 \\
0.230\end{array}$ & $\begin{array}{l}\text { Slice } \\
2 \\
2 \\
2 \\
2\end{array}$ & $\begin{array}{l}\text { AR } \\
1.911 \\
2.547 \\
3.686 \\
4.154\end{array}$ & $\begin{array}{l}\text { Round } \\
0.523 \\
0.393 \\
0.271 \\
0.241\end{array}$ & $\begin{array}{l}\text { Solidity } \\
0.729 \\
0.796 \\
0.591 \\
0.602\end{array}$ \\
\hline
\end{tabular}

Figure 2. Snapshots of txt files obtained after identification of mitochondria in a single cell for 2 timepoints ('Slice' 1 and 2) of a time-lapse movie. Three mitochondria were identified in Timepoint 1 and four in Timepoint 2. The columns 'Major', 'Circ.' and 'AR' are used for quantification of mitochondrial morphology.

B. Plotting of mitochondrial morphology parameters and estimation of mitochondrial fission/fusion frequencies using MATLAB

1. Import the data saved in .txt or .csv format for each yeast cell into MATLAB.

2. Plot the mitochondrial size distribution after collating the data under the column 'Major' of the data files across all timepoints from all the cells. This refers to the length of the 'Major' axis of an ellipse fitted to the mitochondria. Use the same dataset to obtain the mean and standard deviation of the mitochondrial sizes across cells.

3. Plot the circularity and aspect ratio of mitochondria using the data under the column 'Circ.' and 'AR' respectively of the data files across all timepoints from all the cells. Again, obtain the mean and standard deviations of the circularity and aspect ratios across cells using the same data set.

4. Write a script/function to count the number of mitochondria in each frame of the time-lapse movie by enumerating the number of occurrences of each stack position in the first column of the data file.

5. Compare the number of mitochondria in consecutive timepoints to obtain fission and fusion events. For instance, if the number of mitochondria in timepoint 1 is 5 and that in timepoint 2 is 7 , then the number of fission events is $7-5=2.2 \div 12 \mathrm{~s}=0.167 / \mathrm{s}$. Conversely, if the number of mitochondria in timepoint 1 is 5 and that in timepoint 2 is 4 , then the number of fusion events is $5-4=1$ (Figure 1 ).

6. Count the total number of fission and fusion events per cell for the entire time-lapse movie to obtain an estimate of fission and fusion frequencies. For example, if the total number of fission and fusion events for a cell in a $228 \mathrm{~s}$ time-lapse movie are 8 and 9 respectively, then the fission and fusion frequencies for the cell are $0.035 / \mathrm{s}$ and $0.039 / \mathrm{s}$ respectively. Obtain the mean and standard deviation of fission and fusion frequencies of all cells. 
C. Statistical analysis of data

The data for fission and fusion frequencies obtained as described above can be represented in box plots with the central line indicating the median (see Mehta et al., 2019). To obtain the 95\% confidence interval of the median, perform one-way ANOVA ('anova1' in MATLAB) or Kruskal-Wallis Test ('kruskalwallis' in MATLAB). The former is used when data is normally distributed and the latter when data are non-normally distributed. The normality of the dataset is tested using 'chi2gof' function in MATLAB. Significant difference $(P<0.05)$ between control and test groups is then be tested using Tukey's Honestly Significant Difference procedure ('multcompare' in MATLAB).

\section{Recipes}

1. Phosphate buffered saline (10x)

$\begin{array}{lll}\text { Amount } & \text { Component } & \text { Final conce } \\ 80 \mathrm{~g} / \mathrm{L} & \mathrm{NaCl} & 0.137 \mathrm{M} \\ 2 \mathrm{~g} / \mathrm{L} & \mathrm{KCl} & 2.7 \mathrm{mM} \\ 14.4 \mathrm{~g} / \mathrm{L} & \mathrm{Na}_{2} \mathrm{HPO}_{4} & 0.01 \mathrm{M} \\ 2.7 \mathrm{~g} / \mathrm{L} & \mathrm{KH}_{2} \mathrm{PO}_{4} & 1.8 \mathrm{mM}\end{array}$

Adjust the $\mathrm{pH}$ to 7.2

Filter sterilize the solution by passing it through a bottle top filter containing a $0.22 \mu \mathrm{m}$ pore size membrane filter and store at room temperature

2. EMM: Edinburgh Minimal Medium with appropriate supplements

Note: This recipe is taken from http://www-bcf.usc.edu/ forsburg/media.html.

Depending on the strain, medium with appropriate supplements is used. For imaging, liquid EMM is most ideal (Forsburg and Rhind, 2006)

$\begin{array}{lll}\text { Amount } & \text { Component } & \text { Final concentration } \\ 3 \mathrm{~g} / \mathrm{L} & \text { potassium hydrogen phthallate } & 14.7 \mathrm{mM} \\ 2.2 \mathrm{~g} / \mathrm{L} & \mathrm{Na}_{2} \mathrm{HPO}_{4} & 15.5 \mathrm{mM} \\ 5 \mathrm{~g} / \mathrm{L} & \mathrm{NH}_{4} \mathrm{Cl} & 93.5 \mathrm{mM} \\ 20 \mathrm{~g} / \mathrm{L} & \text { glucose } & 2 \% \mathrm{w} / \mathrm{v} \\ 20 \mathrm{ml} / \mathrm{L} & \text { salts } & \\ 1 \mathrm{ml} / \mathrm{L} & \text { vitamins } & \\ 0.1 \mathrm{ml} / \mathrm{L} & \text { minerals } & \end{array}$

Minimal supplemented with amino acids: $E M M+225 \mathrm{mg} / \mathrm{L}$ supplements (ade, leu, his, lys, ura...) as required (each amino acid at $225 \mathrm{mg} / \mathrm{L}$ )

We make amino acid stock solutions at $7.5 \mathrm{mg} / \mathrm{ml}$ (3.75 for uracil) and autoclave the solution for $40 \mathrm{~min}$ at $121^{\circ} \mathrm{C}$ with $15 \mathrm{psi}$ of pressure

\section{Stock solutions}

a. 50x Salt stock 


$\begin{array}{lll}\text { Amount } & \text { Component } & \text { Final concentration } \\ 52.5 \mathrm{~g} / \mathrm{L} & \mathrm{MgCl}_{2} \cdot 6 \mathrm{H}_{2} \mathrm{O} & 0.26 \mathrm{M} \\ 0.735 \mathrm{~g} / \mathrm{L} & \mathrm{CaCl}_{2} \cdot 2 \mathrm{H}_{2} \mathrm{O} & 4.99 \mathrm{mM} \\ 50 \mathrm{~g} / \mathrm{L} & \mathrm{KCl} & 0.67 \mathrm{M} \\ 2 \mathrm{~g} / \mathrm{L} & \mathrm{Na}_{2} \mathrm{SO}_{4} & 14.1 \mathrm{mM}\end{array}$

Filter sterilize the solution by passing it through a bottle top filter containing a $0.22 \mu \mathrm{m}$ pore size membrane filter and store at $4{ }^{\circ} \mathrm{C}$

b. $1,000 x$ Vitamin stock

$\begin{array}{lll}\text { Amount } & \text { Component } & \text { Final concentration } \\ 1 \mathrm{~g} / \mathrm{L} & \text { pantothenic acid } & 4.20 \mathrm{mM} \\ 10 \mathrm{~g} / \mathrm{L} & \text { nicotinic acid } & 81.2 \mathrm{mM} \\ 10 \mathrm{~g} / \mathrm{L} & \text { inositol } & 55.5 \mathrm{mM} \\ 10 \mathrm{mg} / \mathrm{L} & \text { biotin } & 40.8 \mu \mathrm{M}\end{array}$

Filter sterilize the solution by passing it through a bottle top filter containing a $0.22 \mu \mathrm{m}$ pore size membrane filter and store at $4{ }^{\circ} \mathrm{C}$

c. $10,000 x$ Mineral stock

$\begin{array}{lll}\text { Amount } & \text { Component } & \text { Final concentration } \\ 5 \mathrm{~g} / \mathrm{L} & \text { boric acid } & 80.9 \mathrm{mM} \\ 4 \mathrm{~g} / \mathrm{L} & \mathrm{MnSO}_{4} & 23.7 \mathrm{mM} \\ 4 \mathrm{~g} / \mathrm{L} & \mathrm{ZnSO}_{4} \cdot 7 \mathrm{H}_{2} \mathrm{O} & 13.9 \mathrm{mM} \\ 2 \mathrm{~g} / \mathrm{L} & \mathrm{FeCl}_{2} \cdot 6 \mathrm{H}_{2} \mathrm{O} & 7.40 \mathrm{mM} \\ 0.4 \mathrm{~g} / \mathrm{L} & \text { molybdic acid } & 2.47 \mathrm{mM} \\ 1 \mathrm{~g} / \mathrm{L} & \mathrm{KI} & 6.02 \mathrm{mM} \\ 0.4 \mathrm{~g} / \mathrm{L} & \text { CuSO }_{4} \cdot 5 \mathrm{H}_{2} \mathrm{O} & 1.60 \mathrm{mM} \\ 10 \mathrm{~g} / \mathrm{L} & \text { Citric acid } & 47.6 \mathrm{mM}\end{array}$

Filter sterilize the solution by passing it through a bottle top filter containing a $0.22 \mu \mathrm{m}$ pore size membrane filter and store at $4{ }^{\circ} \mathrm{C}$

3. YE: Yeast Extract with supplements

$\begin{array}{lll}\text { Amount } & \text { Component } & \text { Final concentration } \\ 5 \mathrm{~g} / \mathrm{L} & \text { Yeast extract } & 0.5 \% \mathrm{w} / \mathrm{v} \\ 30 \mathrm{~g} / \mathrm{L} & \text { Glucose } & 3.0 \% \mathrm{w} / \mathrm{v}\end{array}$

Supplements: $225 \mathrm{mg} / \mathrm{L}$ adenine, histidine, leucine, uracil and lysine hydrochloride Autoclave the solution for $40 \mathrm{~min}$ at $121^{\circ} \mathrm{C}$ with $15 \mathrm{psi}$ of pressure. To make solid medium, add $2 \%(w / v)$ Difco Bacto Agar prior to autoclaving

\section{Acknowledgments}

This research was supported by the Department of Science and Technology (India)-INSPIRE Faculty Award, the Department of Biotechnology (India) Innovative Young Biotechnologist Award, 
and the Science and Engineering Research Board (SERB, India) Early Career Research Award awarded to V.A. This protocol was adapted from Mehta et al., 2019.

\section{Competing interests}

The authors declare that they have no competing interests with the contents of this article.

\section{$\underline{\text { References }}$}

1. Forsburg, S. L. and Rhind, N. (2006). Basic methods for fission yeast. Yeast 23(3): 173-183.

2. Harwig, M. C., Viana, M. P., Egner, J. M., Harwig, J. J., Widlansky, M. E., Rafelski, S. M. and Hill, R. B. (2018). Methods for imaging mammalian mitochondrial morphology: A prospective on MitoGraph. Anal Biochem 552: 81-99.

3. Mehta, K., Chacko, L. A., Chug, M. K., Jhunjhunwala, S. and Ananthanarayanan, V. (2019). Association of mitochondria with microtubules inhibits mitochondrial fission by precluding assembly of the fission protein Dnm1. J Biol Chem 294(10): 3385-3396.

4. Mishra, P. and Chan, D. C. (2016). Metabolic regulation of mitochondrial dynamics. J Cell Biol 212(4): 379-387.

5. Schindelin, J., Arganda-Carreras, I., Frise, E., Kaynig, V., Longair, M., Pietzsch, T., Preibisch, S., Rueden, C., Saalfeld, S., Schmid, B., Tinevez, J. Y., White, D. J., Hartenstein, V., Eliceiri, K., Tomancak, P. and Cardona, A. (2012).Fiji: an open-source platform for biological-image analysis. Nat Methods 9(7): 676-682.

6. Sprenger, H. G. and Langer, T. (2019). The good and the bad of mitochondrial breakups. Trends Cell Biol 29(11): 888-900.

7. Viana, M. P., Lim, S. and Rafelski, S. M. (2015). Quantifying mitochondrial content in living cells. Methods Cell Biol 125: 77-93.

8. Vowinckel, J., Hartl, J., Butler, R. and Ralser, M. (2015). MitoLoc: A method for the simultaneous quantification of mitochondrial network morphology and membrane potential in single cells. Mitochondrion 24: 77-86.

9. Westermann, B. (2010). Mitochondrial fusion and fission in cell life and death. Nat Rev Mol Cell Biol 11(12): 872-884. 